\title{
Exploratory Analysis of the Factors Affecting Consumer Choice in E-Commerce: Conjoint Analysis
}

\author{
Elena Mazurova ${ }^{1 *}$ \\ 1 Ábo Academy, Turku, FINLAND \\ *Corresponding Author: e.mazurova.turku@gmail.com \\ Citation: Mazurova, E. (2017). Exploratory Analysis of the Factors Affecting Consumer Choice in E- \\ Commerce: Conjoint Analysis. Journal of Information Systems Engineering \& Management, 2(2), 12. doi: \\ $10.20897 /$ jisem.201712
}

Published: March 30, 2017

\begin{abstract}
According to previous studies of online consumer behaviour, three factors are the most influential on purchasing behavior - brand, colour and position of the product on the screen. However, a simultaneous influence of these three factors on the consumer decision making process has not been investigated previously. In this particular work we aim to execute a comprehensive study of the influence of these three factors. In order to answer our main research questions, we conducted an experiment with 96 different combinations of the three attributes, and using statistical analysis, such as conjoint analysis, t-test analysis and Kendall analysis we identified that the most influential factor to the online consumer decision making process is brand, the second most important attribute is the colour, which was estimated half as important as brand, and the least important attribute is the position on the screen. Additionally, we identified the main differences regarding consumers stated and revealed preferences regarding these three attributes.
\end{abstract}

Keywords: brand, colour, position on the screen, conjoin analysis, correlation, human perception, consumer decision making process, e-commerce

\section{INTRODUCTION}

The increase in the competition on the market, as well as mass customization and increased requirements of customers to brands and properties of goods force managers to understand the influence of the different attributes of products that mostly influence on the consumer decision making process. Identification of the most influential attributes allows for increasing the effectiveness of the marketing strategy by focusing on those attributes, leading to higher positive perception of the consumers and as a result to increased volumes of sales, and decreased costs and efforts towards those attributes.

According to previous research, three factors are the most influential on the final purchasing decision of consumers in online shopping: brand, colour and position of the product on the screen. For example, in their work Dick (1990) state that the importance of the brand on consumer perception increases during online shopping due to the limited number of other attributes of the product, which the consumer can examine, such as taste, smell, texture or a complete list of ingredients. As a result, the consumer primarily relies on the brand image and reputation. However, Swiss scientist Max Lüscher (1969) state that using certain colours, it is possible to control the perception of products by the customers as each colour causes a particular predictable reaction of a person and influences his/her emotions in a certain way. Additionally, according to Goolge research (Enquiro, 2005), scientists identified that consumers track the product on the screen according to Golden Triangle pattern and position attribute was being admitted as important and influential on consumer behaviour. However, studying the theoretical background of online consumer behavior, we have not found any comparison analysis of the influence 
of these three factors identifying the most influential of them, even though individual importance of each particular attribute on consumer's decision making process has been analyzed frequently. Thus, in this particular work we will consider the level of influence of three different factors, brand, colour and the position of the product on the screen in the conditions of simultaneous perception by the customers. In this work, we seek to achieve the following research objectives:

1. identify the most influential factor among brand, colour and position on the screen, on online consumer purchasing behavior;

2. assess the level of correspondence between what colours and brands consumers think they prefer and what their actual preferences are based on their observed choices, particularly considering the differences with respect to gender educational level and nationality.

The rest of the paper is structured as follows. Section 2 presents the literature review, focusing on the role of colour, position and brand on perception of online consumers. Section 3 discusses the experiment design and methodology, followed by the results in Section 4. Finally, discussion and conclusions are presented in Section 5.

\section{CONSUMER BEHAVIOUR}

The knowledge about consumer's decision making process and preferences in online purchasing is crucial for building a new marketing strategy or making changes to the existing strategy so that it is oriented to a particular market audience, satisfies consumer's needs and works on increasing sales.

When studying the driving forces of consumer buying behaviour, it is not possible to eliminate various cultural, social, psychological and individual factors from the process as they make a crucial influence on the final choice of a consumer and his/her individual preferences of the products itself and its various attributes, such as brand, colour and other features (Park et al., 2003).

\section{Influence of Colour on Consumer Behaviour}

By using certain colours, it is possible to control the perception of the advertisements and products by the customers. The perception of a colour by people changes depending on the associations related to the colour. According to previous studies, there is a general description of the emotions and associations that different colours evoke (Dick, 1990, Lüscher, 1969).

In his work of 2011 Lauren Labrecque states that the influence of colours on customer perception depends on different factors: associative learning, individual preferences, cultural factors, gender and age preferences, and associations with a particular brand or goods. In the works of Bellizzi et al., (1983), and recent work of Elliot et al. (2007), and Schlack et al. (2007), the perception of colour is considered from the perspective of associative learning, claiming that people tend to have the emotional response on the particular colour based on the associations with objects or situations.

According to the research conducted by Hulbert et al. (2007), there are significant differences between the colour preferences of women and men. Some of them differ only by the percentage of preferences, such as, for example, $76 \%$ against $56 \%$ of preference of the blue colour by women and men, respectively. Other differences are opposite among genders such as, for example, women prefer purple, pink and yellow colours while men mostly prefer black, orange (instead of yellow), brown and green colours.

\section{Position on the Screen and the Golden Triangle}

According to the research performed by Google, positioning on the screen has a significant influence on customer's choice. When scrolling the web-pages and searching for the products, the customer stops only for several seconds on each page and this time must be enough for the product to make the greatest impression on the customer such that the customer is ready to order it (Enquiro, 2005).

According to the study conducted by the University of Tulsa, position takes the third place among the factors that influence customer choice. Other two factors are relevance of the product and its description. Position follows them according to the level of its significance.

According to Google Eye-tracking research (2005), the Golden Triangle area catches the most intense eye scan activity. Consumers restrict scan activity to the Golden Triangle area of the page. If the target good is not placed in the area of the Golden Triangle area, the chances that the customer will stop his/her final choice on the product are very low. Consumer's eyes tend to orient themselves in the upper left corner of the page and then they move down the left side of the page. The scan activity quickly degrades when moving from up to down positions of the objects on the screen. So, first a customer looks to the upper left corner, and it is the initial starting point of the eyes (rectangles 1 and 2), then moving down, scanning the information from left to right (rectangles 4).

This result has a big importance for marketers if they want to attract customer's attention to unpopular products, placing them among popular products in the key locations (Enquiro, 2005). Knowledge about the area 
of the highest consumer's visual attention in the combination with a valuable product is essential for marketing strategy (Tobii Technology Manual, 2008).

\section{Online Brand Influence}

According to previous researches, brand is much more than just a name or a symbol of the company. Brand addresses to the feelings, emotions and subconscious mind of a consumer. Brand evokes the associations, saved in the consumer's memory and aims to differentiate a retailer from its competitors, creating intangible benefits for the customer (Rigaux-Bricmont, 1981; Dick, 1990; Young, 2008; Keller, 1993). According to Dick, A. (1990), the importance of the brand name of the product increases, when there's a limited information about other attributes and characteristics of the product.

Thus, when buying online, customers do not have the possibility to examine many features, characteristics and attributes of a product, which are important for them. So, a customer relies on the brand name, which s/he has already known, in order to decrease the risks and uncertainties associated with an online purchase (Dawar et al., 1994). In the consumer's mind, brand name is strongly associated with and guarantees the quality and features of a product, which customer cannot check by him/herself.

According to Google research, well-known brand works as a natural visual anchor or magnet for the consumer's eyes in the process of online shopping. In contrast to unknown brands, well-known brand for a consumer provides much more information about even an unknown product, which is spread out via media, advertisement, promotion campaigns, world-of-mouth communication and previous use of the brand (Zboja, 2006).

Based on the presented theoretical background we can formulate the following hypotheses:

Hypothesis 1: The distribution of importance between brand, color and position on the screen will be as follows: color is the most influential on consumer's decision-making process attribute, brand is the second one and position is the least influential attribute among three.

Hypothesis 2: The most popular brand, frequently chosen by the participants, will be Fazer and the least popular Chocolate as people will try to avoid choosing an unknown brand.

Hypothesis 3: Red is the most attention catching color and will get the highest number of observations by the respondents.

Hypothesis 4: The distribution of the number of observations among four positions is the following: the highest number of choices will be from the upper left corner, and then in decreasing order: the upper right, bottom left and bottom right corners of the screen.

\section{DESIGN OF EXPERIMENT}

In order to check our hypotheses and evaluate the perception of Brand, Colour and Position on the screen on the consumer decision-making process, we have created a computer experiment, consisting of different consecutive combinations of 6 colours, 4 positions and 4 brands, giving 96 possible combinations. Using the $R$ statistical software environment, 48 combinations of the profiles were generated to be tested, which would allow us analyze all 96 profiles and identify the level of influence of each particular attribute. The choice of the colours is justified by the theory of the colour wheel and individual features of influence of different colours on the consumer behaviour. We have chosen three primary colours: yellow (positive effect on the human mind), blue (favourite among gender), red (the most attention catching); two secondary colours: green (the most pleasant for a human eye with a relaxing effect) and purple (the least associated with the chocolate); and one neutral colour: brown (mostly associated with the chocolate).

We used the RGB web safe palette for choosing the hues of each particular colour according to the content of either red, green or blue. Some features of the chosen hues, such as saturation or lightness, were changed in order to make the colours friendlier for the user's eyes.

Three most popular chocolate brands, present in all stores in Finland: Fazer, Marabou and Panda, were tested in the experiment. Additionally, we have created a nonexistent brand Chocolate, representing the absence of a particular brand and implying that this brand can represent any chocolate brand, as exemplified in Figure 1. Using Photoshop 6.0, the pictures of all possible combinations of 4 logos of the brands and 6 colours of the packages were created (see Figure 1).

Concerning the position of the object on the screen, according to the theory of the Golden Triangle (Enquiro, 2005), the extreme points or extreme rectangles of the Golden Triangle were tested in the experiment,: (i) two upper corners of the screen, rectangles number 1 and 2, with upper left rectangle number 1 expected to take the biggest attention of the participants; and (ii) two lower rectangles of the screen, with rectangle number 2 and rectangle number 4 expected to take the smallest number of participants' observations (see Figure 1). 

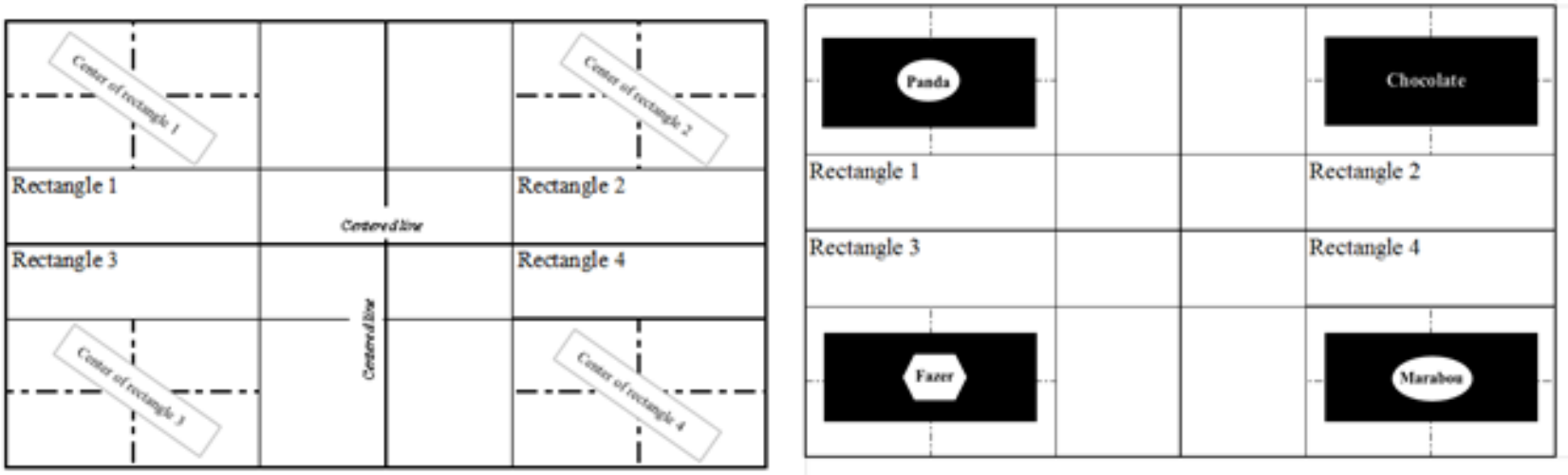

Figure 1. Test example.

Exactly in the center of each chosen rectangle (in order to reduce the error of eye movements) one profile of each combination was place. Participants were chosen randomly among the students and lecturers of Åbo Akademy and University of Turku, divided into two group: Finns and not Finns. Altogether, 40 Finnish people and 20 people of other nationalities were tested. All participants were aged from 18 till 62 years old with an average age of 28.57. Among them there were 24 women and 36 men with different educational background: Bachelor-24 participants, Master Degree-26, PhD-10.

\section{RESULTS}

The data, obtained during the experiment was analyzed with the Excel add-on XLSTAT, using choice-based conjoint analysis. The importance and utility indexes were calculated for the whole sample, as well as for each of the sub-groups: Gender, Education and Nationality.

\section{Importance}

The importance index indicates the level of importance of each particular attribute for a group of participants as potential customers, which allows answering the main research question: which attribute of a product, brand, colour or the position on the screen, mainly influences on the consumer's final choice.

Utility index indicates the likelihood that a particular Brand, Colour or the position on the screen will be chosen by a customer when performing online shopping - the higher the index is (positive), the more likely that a particular attribute will be chosen by a customer. The negative index indicates that a particular attribute-level discourages people from choosing it.

The index of importance indicates that among the whole sample of the participants the Brand attribute is the most important and influential for the customer's choice of the product. The second most important attribute is colour, having the index of importance almost twice lower than the Brand (60.9/32.8). The least influential attribute for consumer choice is the position of the product on the screen, having the index of importance for the respondents equal to 6.3 .

Comparing the indexes of importance for the whole group of respondents as well as for the Gender, Education and Nationality sub-groups, we can observe that the tendency is the same. However, within groups there are differences of priorities of the attributes. Regarding gender, brand and colour attributes have a slightly higher importance for male respondents than for female. However, position attribute is significantly more important for female respondents than for male ones.

Considering the educational level of participants, the highest importance Brand factor has for Bachelors and the smallest importance - for doctors. Within this group, colour attribute has the highest importance for Masters than for respondents with Bachelor or PhD degree. And position attribute has very high index for respondents with $\mathrm{PhD}$ degree compared to the Bachelor or Master sub-groups.

With respect to nationality, we can see that Brand is more important for Finnish respondents than for NonFinnish ones. The indexes of importance of the colour attribute are not very distinctive for both sub-groups. However, for non-Finnish participants the position attribute is almost three times higher than for Finnish.

\section{Utilities}

Considering the indexes of Utilities, it can be observed in Table 2 that the most popular brand that is mostly likely to be chosen by the respondents is Fazer; the most popular colour among participants is blue and the most preferable position of the product on the screen is upper left corner. 
Table 1. Importance values obtained in the conjoint analysis.

\begin{tabular}{|l|l|l|l|l|l|l|l|l|}
\hline \multirow{2}{*}{} & \multirow{2}{*}{ All } & Fem & Male & Bach & Mast & PhD & Fin & $\begin{array}{l}\text { Non- } \\
\text { Fin }\end{array}$ \\
\hline Brand & 60.9 & 59.34 & 61.65 & 69.04 & 52.73 & 50.16 & 63.38 & 52.21 \\
\hline Colour & 32.77 & 27.17 & 35.99 & 26.30 & 42.30 & 29.6 & 31.94 & 35.48 \\
\hline Position & 6.32 & 13.48 & 2.34 & 4.65 & 4.96 & 20.23 & 4.674 & 12.3 \\
\hline
\end{tabular}

Table 2. Summary table of utilities for brand, colour and position on screen.

\begin{tabular}{|l|l|l|l|}
\hline & Most preferable & Less preferable & Least preferable \\
\hline Brand & Fazer (0.67) & $\begin{array}{l}\text { Marabou } \\
\text { Panda }\end{array}$ & Chocolate (-0.729) \\
\hline Colour & Blue (0.386) & $\begin{array}{l}\text { Brown } \\
\text { Yellow }\end{array}$ & $\begin{array}{l}\text { Green }(-0.367) \\
\text { Purple }(-0.017) \\
\text { Red (-0.045) }\end{array}$ \\
\hline Position & Upper-left (0.075) & Upper-right & $\begin{array}{l}\text { Bot-left (-0.071) } \\
\text { Bot-right (-0.057) }\end{array}$ \\
\hline
\end{tabular}

Table 3. Kendall analysis indexes for brand and colour.

\begin{tabular}{|l|l|l|l|l|l|l|l|l|}
\hline \multirow{2}{*}{} & \multirow{2}{*}{ Sample } & \multicolumn{2}{|l|}{ Gender } & \multicolumn{3}{|c|}{ Education } & \multicolumn{2}{l|}{ Nationality } \\
\cline { 3 - 9 } & & Fem & Male & Bach & Master & PhD & Fin & $\begin{array}{l}\text { Non } \\
\text {-Fin }\end{array}$ \\
\hline Brand & 0.01 & -0.18 & 0.14 & 0.16 & -0.04 & -0.26 & 0.01 & 0.00 \\
\hline Colour & 0.20 & 0.23 & 0.18 & 0.22 & 0.22 & 0.12 & 0.21 & 0.18 \\
\hline
\end{tabular}

Table 4. $\mathrm{t}$-test $\mathrm{p}$-values for the comparison of brand and colour

\begin{tabular}{|l|l|l|l|l|l|}
\hline & Fem/Mal & Fin/non-Fin & Bach/Mast & Bach/PhD & Mast/PhD \\
\hline Brand & 0.056 & 0.48 & 0.2 & 0.08 & 0.2 \\
\hline Colour & 0.30 & 0.38 & 0.48 & 0.24 & 0.2 \\
\hline
\end{tabular}

The least preferable Brand within the whole sample is Chocolate; the least preferable colours are green, purple and red; the least preferable positions of the product on the screen are bottom left and bottom right.

\section{Comparison of Stated and Revealed Preferences}

In order to evaluate the correlation between what respondents think their preferences are and what they actually choose when shopping online, we use the Kendall correlation and compare the stated (the ratings that participants stated in the questionnaire) and revealed (results of actual preferences) preferences of the respondents as seen in Table 3. As the average correlation measures among the groups are very low (lower than 0.2), we can conclude that there is no significant relationship between the rating of the brands and colours, made by the participants in the questionnaire and during the experiment and estimated by the conjoint analysis.

However, as some of these indexes are higher than 0.2, we still can detect the possible differences between ratings among the different groups. We executed t-test analysis. If the p-value is lower than 0.1 , than we can conclude that there is statistical significant difference between the groups. The results are listed in the Table 4 .

We can see that there is a statistical significant difference between Female and Male groups and between Bachelor and $\mathrm{PhD}$ groups in Brand rating. In general, men can evaluate their brand preferences more precisely than women as well as participants with a Bachelor level of education evaluate their brand preferences more precisely than $\mathrm{PhD}$ respondents. Otherwise, among all other groups there is no statistical significant difference. 


\section{DISCUSSION}

In this particular research work we have implemented a comparison analysis of colour, brand and position on the screen, three attributes of a product that have the important influence on customer's perception and final purchasing decision. Using conjoint analysis we analyzed results of the experiment and identified brand as the most influential attribute of a product in online shopping. This result is not affected by gender, nationality or level of education. Despite the fact that this result contradicts our first and main hypothesis, the results are impressive, as the gap between the brand and the second most influential factor, colour, is twice in magnitude. Thus, we can conclude that when building their marketing strategy of the design and promotion of goods, online the marketing managers should first consider the level of influence of the brand image and reputation on consumers. Even if the colour of the product is unattractive for the customer, the influence of the brand will twice overlap this negative perception by its impact strength. Considering different options of location of the product on the screen of online shop, marketing managers should not focus a lot on this attribute, as, according to the findings, the influence of this attribute on the consumer decision making process is minimal, compared to colour and brand.

Among all educational groups, respondents with Master Degree assign the biggest attention to the Colour attribute, and Bachelors assign to the Brand attribute. Women pay much more attention to the location of the products on the screen then men, as well as consumers with a $\mathrm{PhD}$ degree over other respondents with the Bachelor or Master Degree and foreigners over Finnish consumers. For foreigners, Brand attribute is slightly less important than for Finnish people.

Furthermore, in the process of the research we have identified that the most preferable brand of chocolate is Fazer and the least preferable is a factual absence of brand or unknown brand for both Finnish and non-Finnish respondents. Thus, the results support our second hypothesis, based on the observations of Dick, A. (1990) confirming that in online shopping, when there are limitations on the features of the product, that consumers can examine by him/herself, then the consumer fully relies on the brand reputation in order to decrease the chances of an unsuccessful purchase. In lack of a known brand, consumer prefers to avoid a brand, which s/he is not familiar with.

Besides, we also identified the consumer's preferences of the colours for a particular good, and they are Blue, Brown and Yellow. The least preferable colours for the consumers in our experiment were Green, Purple and Red. Thus, regarding the colour preferences, we can conclude that people follow the preferences in their colour choice, based on the associations that these colours evoke in case of a particular product, as well as associations to the particular brand name. For example, as the blue colour is strongly associated with the chocolate brand Fazer, and brown colour is associated to the chocolate itself. While green is identified as the most pleasant colour to the human eyes by the colour theory, but it is not associated with the chocolate taste. Paradoxical were the results for the Yellow and Red colours as both of them are considered as attention catching colours, though with different features; while Yellow positively influences the consumer perception, Red is a colour of aggressiveness and at the same time the most attention catching colour. Thus, we expected that Red will be the most popular preference of the participants, while Yellow will have lower importance for the respondents. However, in the experiment we obtained opposite results, contradicting our third hypothesis.

Considering the position preferences, as we expected, most of the participants assigned their preference to the upper sides of the screen -the right and the left ones, while the least comfortable for observations were the bottom positions, confirming our 4th hypothesis. We also found that there are differences regarding which position on the screen consumers prefer. While women prefer more the upper right position, men prefer the upper left position. The same tendency is observed among the participants with different educational levels: the preferences of respondents with Master degree are similar to female respondents and Bachelor and $\mathrm{PhD}$ preferences are similar to male ones.

In our research we were also able to answer our research question concerning correlation between personal preferences of consumers of colours and brands and their actual final choice. We can surely say that consumers cannot identify their preferences accurately and the answers regarding their preferences are completely different from their actual choices of the products, as well as their personal rating of the importance of the factors. The factors that consumers consider as the most important, does not usually match the actual rating, made by the consumers in the real purchasing decision-making process.

Thus, in general we can conclude that some of the results of the experiment matched our initial assumptions and hypotheses, and others contradicted and offered surprising observations. However, we should notice that all the results are significant and can be used in the process of developing the marketing strategy of the product design and promotion in online shops, as well as in the further researches.

For further research we would propose to study the influence of different colour combinations in the same starting conditions. Also, in this particular research work, due to small sample of participants, we have not focused 
on the consideration of the influence of cultural differences on the simultaneous perception of colours, brand and positions on the screen perception.

\section{REFERENCES}

Bellizzi, J., Crowley, A. and Hasty, R. (1983). The effects of colour in store design. Retail, 59(1), 21-45.

Dawar, N. and Parket, Ph. (1994). Marketing Universals: Consumers use of brand name, price, physical appearance, and retailer reputation as signals of product quality. Market, 58, 23-57.

Dick, A. (1990). Memory-based inferences during consumer choice. Consumer Research, 17, 82-93.

Elliot, A., Maier, M., Moller, A., Friedman, R.. and Meinhardt, J. (2007). Colour and psychological functioning: the effect of red on performance attainment. Experimental Psychology, 136(1), 154-168.

Elliot, A. and Niesta, D. (2008). Romantic red: red enhances men's attraction to women. Personality and Social Psychology. 95(5), 10-17.

Enquiro, G. (2005). Google eye-tracking report. Eyetools and Did-It, 156-185.

Eye tracking as a tool in package and shelf testing. (2008). Tobii Technology Manual. Available at: http:/ /www.tobiipro.com. (Accessed 30 March 2016).

Hulbert, A.C. and Ling, Y. (2007). Biological components of sex differences in colour preference. Current. Biology, 17, 24-37.

Keller, K. (1993). Conceptualizing, Measuring, and Managing Customer-Based Brand Equity, Marketing Research, 29, 1-22.

Labrecque, L. and Milne, G. (2011). Exciting red and competent blue: the importance of colour in marketing. Academic Marketing Science, 35-47.

Lüscher, M. (1969). The Lüscher colour test, Simon \& Schuster, 35-65.

Park, C. Kim, Y. (2003). Identifying key factors affecting consumer purchase behaviour in an online shopping context. International Journal of distribution and Management, 3, 37-67.

Rigaux-Bricmont, B. (1981). Influence of Brand Name and Packaging on Perceived Quality. Association for Consumer Research, 9, 472-477.

Robbins, J. (2006). Web Design in a Nutshell, O’Reilly Media, 35-67.

Schlack, A. and Albright, T. (2007). Remembering visual motion: neural correlates of associative plasticity and motion recall in cortical area. Neuron, 53, 81-89.

Young, S. (2008). Five Principles for packaging new product. Available at: http:// www.brandpackaging.com/. (Accessed 23 February 2016).

Zboja, J. (2006). The impact of brand on consumer purchase intentions. Asian Market, 4, 23-35. 